\title{
Country Differences in Ultimatum Wage Bargaining with a Real Task: Evidence from Greece, Spain and the UK*
}

\author{
Negociación salarial tipo ultimátum con tarea \\ real: diferencias entre Grecia, España y Reino \\ Unido
}

\author{
Aurora García-Gallego \\ Ainhoa Jaramillo-Gutiérrez \\ Universitat Jaume I \\ Nikolaos Georgantzís \\ Universitat Jaume I \\ Burgundy School of Business
}

\begin{abstract}
From experiments run in Greece, Spain and the UK, this paper studies ultimatum bargaining over the wage paid in order to have a subject perform a given real task. Compared with Greece and Spain, significantly higher wage offers and lower acceptance probabilities are found in the UK. These effects lead to higher wages in the UK. Country differences in both employer and employee behavior have a clear gender component. Specifically, we find that Greek and Spanish females offer lower wages than British females. Contrary to what is obtained for UK subjects, Greek and Spanish females reject more than males.
\end{abstract}

Keywords: ultimatum game, gender differences, experiments.

JEL Classification: C91, D03, J16, J3.

\section{Resumen}

Realizamos experimentos en Grecia, España y Reino Unido para estudiar la negociación salarial tipo ultimátum por la realización de una tarea real. Encontramos ofertas salariales significativamente más altas y menor probabilidad de aceptación en Reino Unido que en los otros dos países, lo que conlleva salarios más altos en Reino Unido. Las diferencias en el comportamiento de los sujetos tienen un claro componente de género. Concretamente, encontramos que las mujeres griegas y españolas ofrecen salarios menores que las británicas. Además, en Grecia y España se observa una mayor tasa de rechazo por parte de las mujeres que de los hombres.

Palabras clave: juego del ultimátum, diferencias de género, experimentos.

Clasificación JEL: C91, D03, J16, J3.

* The authors acknowledge financial support by the Spanish Ministerio de Ciencia, Innovación y Universidades (grant RTI2018-096927-B-I00), Universitat Jaume I (grant UJI-B2018-76) and ANR (grant ANR-18-CE26-0018, GRICRIS). 


\section{Introduction}

Behavioral differences across countries are usually attributed to historical, geographical and cultural factors. Furthermore, the overall influence of other social and macroeconomic environmental conditions can also be captured by laboratory data, because norms and beliefs are transferred from the real world to the lab.

Differences in social and cultural environments have been shown to explain behavioral variability in a number of decision making contexts. Among these contexts, the Ultimatum Game (UG) has been often used as a vehicle for assessing behavioral differences across countries. In fact, as Camerer and Fehr (2004) state, the UG is a useful tool for the examination of cultural differences in a negotiation context capturing subjects' monetary expectations and fairness notions presumably dictated at least partly by local social norms. Several contributions in the literature confirm this fact.

In the UG, one proposer offers a share of a fixed amount of money and a responder decides whether to accept or reject the offer. If the offer is accepted, the proposed share is made effective. Otherwise, proposer and responder earn nothing.

Among the earliest, and probably the most well-known study of country differences using the UG, is the one by Roth et al. (1991). The authors compare ultimatum bargaining and multi-person market environments in Israel, Japan, the United States and Yugoslavia. They find differences in bargaining behavior in the four countries, which are tentatively attributed to cultural differences. In Henrich et al. (2001), the authors recruited non-student subjects from 15 small-scale societies in 12 countries and found large group differences in the offers and in the rejection rates. In their follow up studies, Henrich et al. (2006, 2010), the authors confirm that cultural differences explain more variance than individual differences. ${ }^{1}$

Another important contribution is the meta-analysis by Oosterbeek, Sloof and van de Kuilen (2004). They use data obtained from 37 papers which form a total of eight geographical groups. Contrary to Henrich et al. (2001), the authors find that country differences are reflected only on respondents' behavior and not on the behavior of proposers. The authors conclude that these differences cannot be attributed to cultural traits as the ones used by Hofstede (1991) and Inglehart (2000).

In Chuah et al. (2007, 2009), a cross-national UG is used to analyze differences in behavior between Malaysian Chinese and the UK subjects. They find cultural differences in both intra- and inter-national interactions, although they find a small effect of demographic variables on subjects' behavior.

A more general analysis is made by Botelho et al. (2001), whose experimental design controls for demographics. The authors test for cultural differences in Russia

${ }^{1}$ In the three studies by Henrich et al. (2001, 2006, 2010), the responder's willingness to reject is interpreted as a measure of costly punishment. Although we are not against this interpretation, we do not feel our data are in position to disentangle this from a simple non-acceptance to participate in an unfair outcome and we keep this standard notion of rejection throughout the paper. 
and the United States. Although there is a country effect, the authors conclude that cultural differences are more complex than the factors captured by either nationality or gender alone.

In this paper, we focus on the role of gender as an explanatory factor of differences across countries in ultimatum wage bargaining behavior. Concerning the role of gender in human decision making, Eckel and Grossman (2008) review the results from two ultimatum experiments, Solnick (2001) and Eckel and Grossman (2001), searching for evidence of systematic differences in the behavior of men and women. Although there are several differences in the design of these two experiments, there are considerable similarities in the results. The differences are mainly two. First, while Solnick (2001) conducts a one-shot UG game in which the responder has to decide about the minimum acceptable offer without being aware of the offer proposed, ${ }^{2}$ Eckel and Grossman (2001) run a repeated-play (eight periods) UG using a directresponse method. ${ }^{3}$ Second, Solnick (2001) reveals players' gender in the second treatment, while subjects have no information on their partner's identity in Eckel and Grossman (2001). As far as the results are concerned, both studies find small differences in the offers made both by men and women. Moreover, both conclude that offers to women are, on average, lower than offers made to men, independently of the sex of the proposer. The divergence in the results focuses on the behavior of the responder. While the overall rejection rates are similar, Solnick (2001) reports higher rejection rates in offers made by women, while Eckel and Grossman (2001) find higher rejection rates for offers made by men. ${ }^{4}$ The difference is conjectured to originate from the fact that risk is absent for the responder in this setting.

There are several studies which confirm the view that women tend to be more risk averse than men (García-Gallego et al., 2012; Filippin \& Crosetto, 2016). Consistent with this explanation are the findings of Croson and Buchan (1999) who examine gender differences in the trust game ${ }^{5}$ using data from four countries: The United States, China, Japan and Korea. They find that, while no significant effect of gender is found with respect to the proposer, when making the risk-less decision of responder, women return significantly more than their male counterparts. However, in a related paper using the Spanish dataset alone, we show that gender differences in the UG are not due to risk attitude differences (García-Gallego et al., 2012).

${ }^{2}$ This is like an UG played simultaneously. If the proposer's offer equals or exceeds the responder's minimum acceptable offer, the offer is accepted, and the pie divided according the proposer's proposal. Solnick (2001) explicitly names this as the UG played according to the strategy method.

${ }^{3}$ Under the direct-response method, the proposer makes an offer which is presented to the responder, who then decides whether to accept or reject.

${ }^{4}$ In particular, the major difference is found in the rejection rates for offers made by women to women.

${ }^{5}$ In the standard trust game, the proposer and the responder start with the same endowment. The proposer then has the opportunity to give a portion of his endowment to the responder. Whatever amount the proposer decides to give to the responder will be tripled before it is passed on to the responder. The responder then has the option of returning any portion of this tripled amount to the proposer. 
Eckel and Grossman (2001) report substantial differences in ultimatum play by African-American subjects. Black subjects are clearly more egalitarian in their proposals. In addition, blacks are more likely to reject an offer of a given size. The authors find a significant difference in the distributions of offers made by black and nonblack subjects.

Saad and Gill (2001) conduct a one-shot UG in which subjects randomly face a subject of the same or contrary gender. Each subject knows the sex of his/her partner. They find that males make more generous offers when pitted against a female. Furthermore, females made equal offers independently of the other's sex.

However, none of these papers addresses the issue of how gender effects depend on the subject pool. In order to answer the question whether gender effects depend on cultural differences, we compare behavior of subjects from three subject pools of university students from Greece, Spain and the UK.

Our analysis is based on a series of experimental sessions which do not ex ante control for the composition of pairs in terms of gender. We frame ultimatum bargaining as a situation in which proposers are employers and responders are employees who are offered a salary in order to perform a given task. Among a number of novel design aspects introduced in these experiments, the most prominent feature is that employees accepting a given salary have the obligation to perform a real task.

Our main finding is that gender differences significantly depend on the subject pool, with Greek and Spanish female-responders being more likely to reject a given offer than men-responders, while British females exhibit the contrary tendency.

The paper is organized as follows. In Section 2 we summarize the main design features of the experiment. In Section 3 the main results are discussed. Section 4 concludes. An appendix at the end of the paper includes some extra tables and the instructions given to experimental subjects.

\section{Experimental design}

In the basic UG, two players, proposer and responder, are offered a fixed amount of money which has to be shared between them in the following way: the proposer suggest a split which may then be accepted or rejected by the responder. If accepted, the split takes place as suggested by the proposer, and if not, then both players earn nothing. In the salary negotiation framing used here, employer/employee pairs negotiate over their respective shares from a 10 monetary units (m.u. hereafter) profit earned from a given task performed by the employee. In the experiment, the task is real and a unit of it corresponds to filling 20 numbered envelops with their corresponding numbered single-page letters. The role of this feature on the UG is studied by García-Gallego et al. (2008). As we report there, apart from realism, it makes responders more demanding yielding higher offers and fairer actual splits of the pie. 
Three sessions were run, respectively, in three European countries. Specifically, the first session took place in Greece (GR), in the Computer Lab of the Economics Department of the University of Macedonia. The second session took place in Spain (SP), at the Laboratorio de Economía Experimental of the Universitat Jaume I, Castellón. The third session was run in the UK, in the Computing Laboratory of the Economics Department of the University of Aberdeen, Scotland.

Each experimental session was divided into two different sub-sessions: One during which ultimatum salary negotiation took place and another one, in which employees performed their real task obligations. After this, all subjects were paid as explained below. The first sub-session consisted of two parallel procedures. Namely, i) randomly formed employee-employer pairs ${ }^{6}$ play the salary negotiation UG, which is repeated over a randomly determined number of periods ranging between 30 and 35 , and $i$ ) subjects respond to a payment-card type of control question designed to elicit subjects' beliefs in form of their valuations (certainty equivalent) of the game. Each subject's role was kept fixed along the whole session.

In five randomly chosen periods of the main experiment, a question is presented to the subjects in an incentive-compatible design to control for variations in a subject's valuation of the game due to learning and/or due to changing from a hypothetical to an incentive compatible design. The hypothetical valuations of the game are denoted as $H G V^{7}$ and the five incentive compatible ones by $I C G V_{1}$ to $I C G V_{5}$. Given the lack of any systematic hypothetical bias (measured as differences between hypothetical and real valuations), in the econometric models, we have used Certainty Equivalent which are constructed as the average of each employer/employees' valuations obtained as responses to the hypothetical and the incentive compatible formats of the control questions.

After the negotiation periods were completed and data were collected for each session, five periods were randomly chosen by the computer to determine each employer-subject's earnings and each employee-subject's salaries and real task obligations. Real rewards were paid to employees at the end of the task-performing sub-session, while employers were rewarded just after the end of the salary negotiation sub-session.

A total of 60 subjects ( 10 employers and 10 employees per session) participated in this experiment. Subjects were university students studying economics-related topics and they were assigned once to a single session. Each session lasted, on average, one and a half hours. Average per subject earnings were slightly below $25 €$ in Spain and Greece, and slightly below $25 £$ in the UK. Specific software was written using z-Tree toolbox (Fischbacher, U., 2007).

${ }^{6}$ Subjects in each session were divided into two separate matching groups. Differences across groups within the same session were found not to be statistically significant, and data reported here are the result of pooling across groups.

7 Each subject responds to a payment-card type of control question designed to elicit subject's valuation (certainty equivalent) of the game. See the Questionnaire subsection in the Appendix C. 
Table 1 describes some details of the experimental data obtained: the number of subjects, the males and females numbers and the number of markets in each treatment.

TABLE 1

MAIN CHARACTERISTICS OF THE EXPERIMENT

\begin{tabular}{|c|c|c|c|c|}
\hline Treatments & N & Male & Female & Markets (Pairs) \\
\hline \hline GR & 20 & 9 & 11 & 10 \\
\hline SP & 20 & 6 & 14 & 10 \\
\hline UK & 20 & 12 & 8 & 10 \\
\hline Total & 60 & 27 & 33 & 30 \\
\hline
\end{tabular}

\section{Results}

In this section we present the analysis of our experimental data. Although the number of independent markets is small, the repeated nature of our game adds statistical robustness to the analysis. Specifically, we have taken into consideration the first 33 periods, the maximum number of periods for which we have data for all treatments.

\subsection{General results and descriptive statistics}

The first step of our analysis is to assess whether behavioral differences exist among subjects from Greece, Spain and the UK. ${ }^{8}$ In this subsection we present some descriptive statistics. In Table 2, we provide offer averages by country and by gender. The table also includes hypothetical game valuations (HGV) of subjects as well as incentive compatible game valuations by player type (ICGVer for employers and $I C G$ Vee for employees). Finally, this table includes salary averages considering accepted offers as salaries. ${ }^{9}$ No statistically significant differences are found in hypothetical game valuations across countries. This means that, before starting the experiment, subjects from the three countries have similar hypothetical valuations of the game. However, incentive compatible game valuations exhibit some differences. Greek and Spanish employee-subjects' valuations in the incentive compatible format are lower than the British employee-subjects' valuations.

\footnotetext{
${ }^{8}$ For this purpose, we use per subject averages as independent observations.

9 Zero payoffs due to a rejection are dropped from the sample.
} 
Overall, offers present differences across countries. Mann-Whitney (M-W) tests confirm that offers in the UK are significantly higher (4.97) than in the other two countries (4.09 in Spain and 4.06 in Greece). Moreover, offers in the UK almost coincide with the $50 \%-50 \%$ split of the pie.

TABLE 2

DESCRIPTIVE STATISTICS

(Mean, Standard Deviation and M-W tests)

\begin{tabular}{|l|c|c|c|c|c|c|c|c|c|}
\hline & \multicolumn{3}{|c|}{ Greece } & \multicolumn{3}{c|}{ Spain } & \multicolumn{3}{c|}{ UK } \\
\cline { 2 - 12 } & Overall & Males & Females & Overall & Males & Females & Overall & Males & Females \\
\hline Offer & 4.06 & 4.11 & 3.98 & 4.09 & 4.53 & 3.80 & 4.97 & 4.91 & 5.06 \\
\hline (St.D.) & $(0.22)$ & $(0.20)$ & $(0.26)$ & $(1.18)$ & $(0.34)$ & $(1.47)$ & $(0.40)$ & $(0.40)$ & $(0.44)$ \\
\hline HGV & 5.13 & 4.89 & 5.32 & 4.65 & 4.75 & 4.61 & 4.45 & 3.92 & 5.25 \\
\hline (St.D.) & $(1.55)$ & $(1.24)$ & $(1.81)$ & $(1.36)$ & $(0.76)$ & $(1.57)$ & $(2.44)$ & $(1.68)$ & $(3.91)$ \\
\hline ICGVer & 5.86 & 5.89 & 5.81 & 5.33 & 5.33 & 5.32 & 5.09 & 5.32 & 4.74 \\
\hline (St.D.) & $(1.18)$ & $(1.28)$ & $(1.20)$ & $(0.59)$ & $(0.26)$ & $(0.77)$ & $(0.91)$ & $(0.93)$ & $(0.87)$ \\
\hline ICGVee & 4.12 & 3.98 & 4.18 & 4.33 & 4.14 & 4.38 & 5.45 & 5.54 & 5.31 \\
\hline (St.D.) & $(0.45)$ & $(0.47)$ & $(0.47)$ & $(0.78)$ & $(0.20)$ & $(0.87)$ & $(0.70)$ & $(0.84)$ & $(0.47)$ \\
\hline Salaries & 4.21 & 4.28 & 4.08 & 4.55 & 4.59 & 4.46 & 5.19 & 5.11 & 5.26 \\
\hline (St.D.) & $(0.16)$ & $(0.12)$ & $(0.19)$ & $(0.18)$ & $(0.19)$ & $(0.01)$ & $(0.32)$ & $(0.20)$ & $(0.36)$ \\
\hline & \multicolumn{7}{|c|}{ M-W Tests between countries $(p$-values) } & & \\
\hline & \multicolumn{7}{|c|}{ Greece-UK } & \multicolumn{7}{c|}{ Greece-Spain } & & Spain-UK \\
\cline { 2 - 13 }$y$ & Overall & Males & Females & Overall & Males & Females & Overall & Males & Females \\
\hline Offer & 0.0002 & 0.0039 & 0.0209 & 0.1735 & 0.0871 & 0.6698 & 0.0052 & 0.2008 & 0.0105 \\
\hline HGV & 0.2303 & 0.1604 & 0.9338 & 0.1381 & 0.6701 & 0.1341 & 0.9782 & 0.3424 & 0.2843 \\
\hline ICGVer & 0.1978 & 0.6304 & 0.1489 & 0.2256 & 0.3923 & 0.3938 & 0.2501 & 0.1869 & 0.4542 \\
\hline ICGVee & 0.0004 & 0.0196 & 0.0140 & 0.1400 & 0.5637 & 0.2022 & 0.0025 & 0.0442 & 0.0415 \\
\hline Salaries & 0.0002 & 0.0201 & 0.0082 & 0.0007 & 0.0833 & 0.0055 & 0.0002 & 0.0455 & 0.0066 \\
\hline
\end{tabular}

Figure 1 shows a positive time trend of offers which is a common feature for the three countries. From early periods, British subjects make offers which, on average, exceed 4.5, while Spanish and Greek subjects start their offers from below 3.5 and raise them over time.

Referred to Table 2, offers made by British females are significantly higher than offers made by females in Spain and Greece. In fact, British females make offers which are, on average, even higher than the $50 \%$ of the pie, while Spanish and Greek females offer their employees a share which lies below $40 \%$.

As far as males are concerned, in the three countries males' offers are higher than 4 m.u., although the offers by male subjects in the UK are significantly higher than those offered by male subjects in Greece. 


\section{FIGURE 1}

\section{EVOLUTION OF OFFERS BY COUNTRY}

(Average per period)

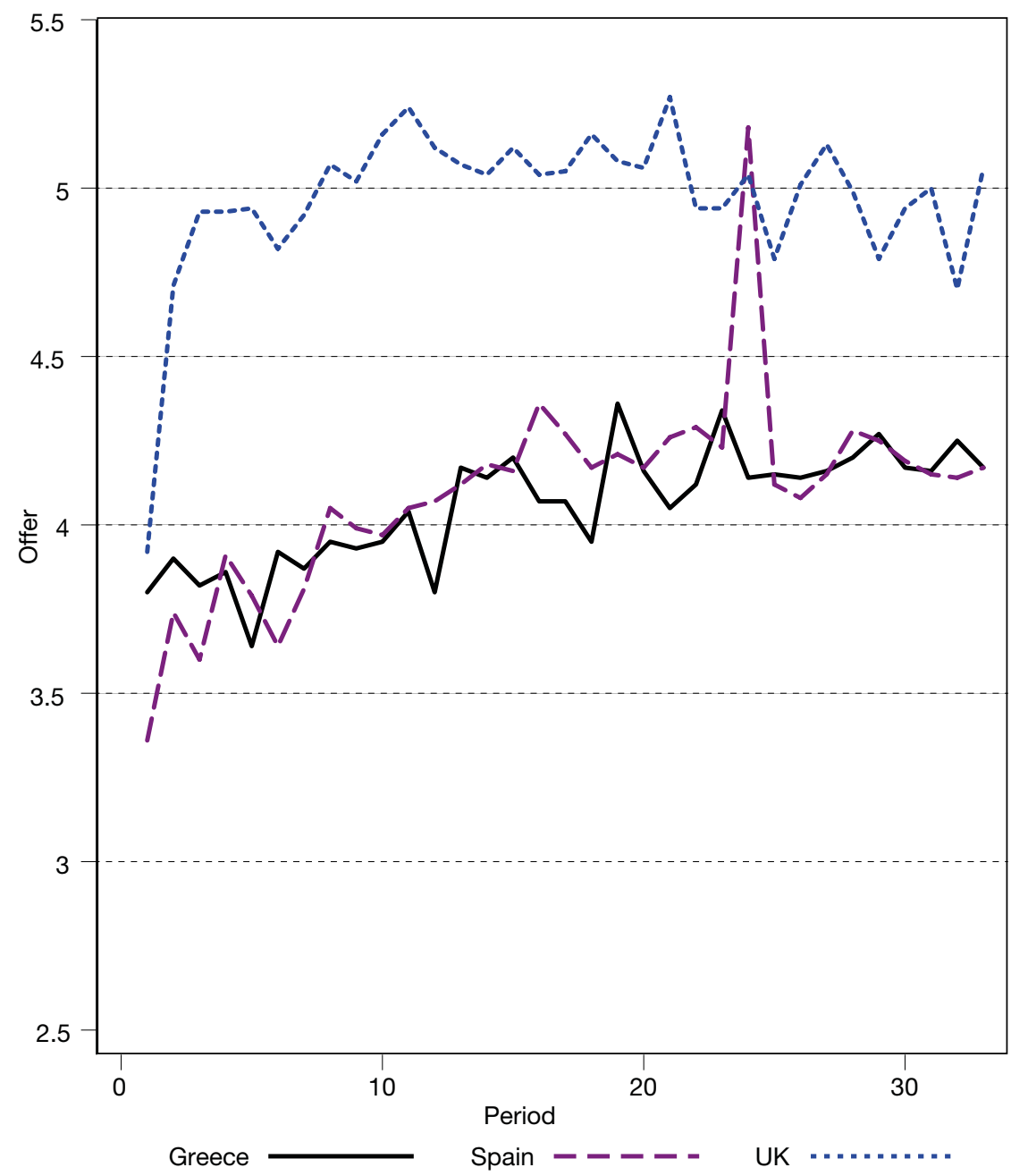

Figure 2 shows the evolution of offers by country and gender. Note that females' offers in the UK are always above the offers made by Greek and Spanish females. The trend is positive for males in the three countries as well as for females in GR and SP. We confirm that Greek and Spanish females offer lower wages than females in the UK. Spanish and Greek females seem to behave in similar ways over time and differently than British females, who systematically make higher offers. 
FIGURE 2

\section{EVOLUTION OF OFFERS BY EMPLOYER'S GENDER}

(Average per period)
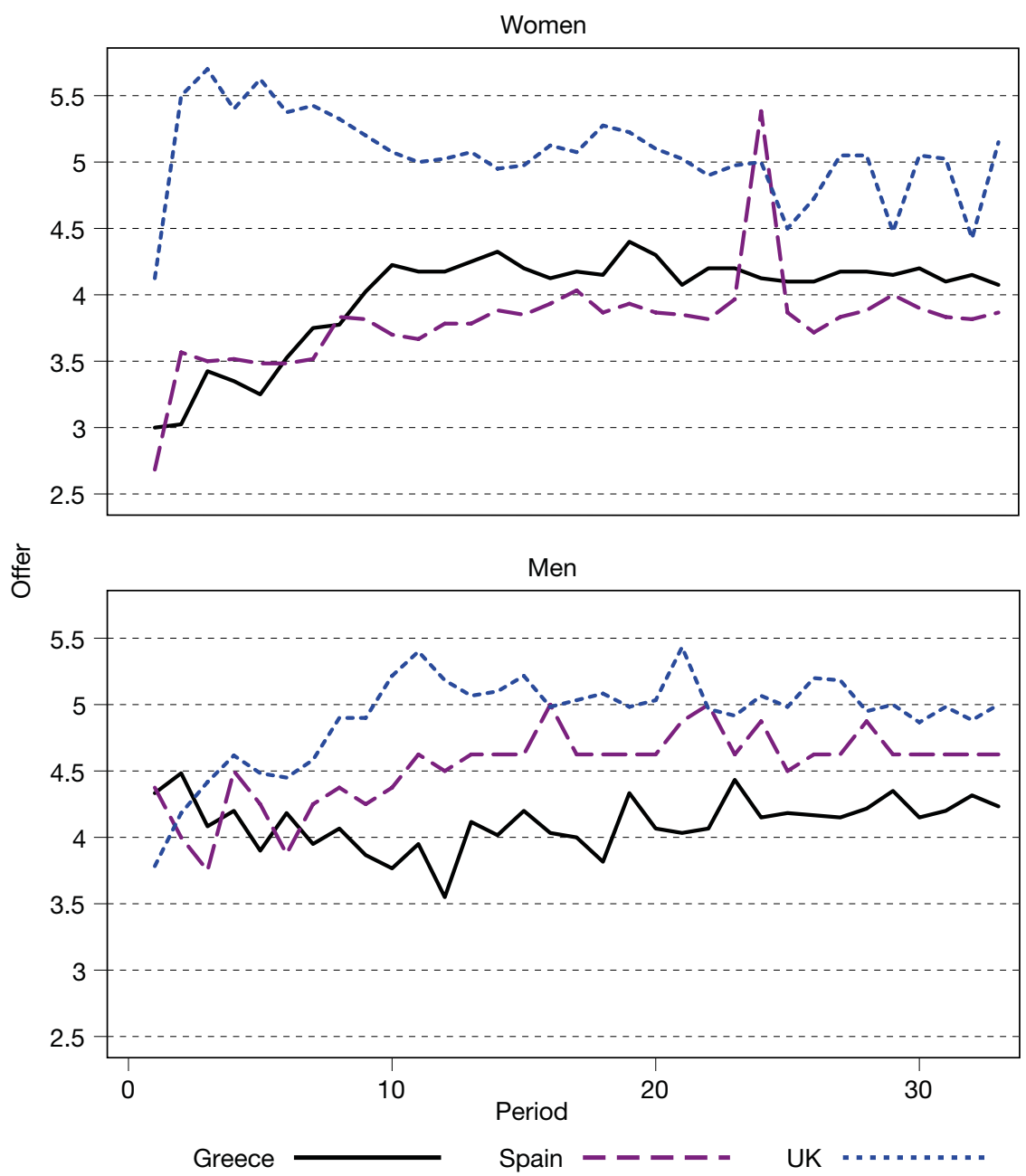

In Table 3 we present information on offers percentage, by country, gender and offers' interval. Approximately $91 \%$ of all offers (301/330) by British subjects are above 4.2 m.u. Offers in Spain and Greece exhibit a distribution with two peaks. Concerning Spain, one peak is observed on the 3.7-4.2 interval, which corresponds to the $30 \%(100 / 330)$ of all offers. A proportion of $40 \%(127 / 330)$ of all offers falls within the 4.7-5.2 interval. The remaining 50 offers fall between these two modes. In the case of Greek subjects, the two peaks correspond to offers in the intervals 3.7-4.2 m.u. (37\% of all offers, 122/330) and 4.2-4.7 (43\% of all offers, 143/330). The data by gender follow the same pattern. 
TABLE 3

PERCENTAGE OF OFFERS, BY INTERVALS

\begin{tabular}{|c|c|c|c|c|c|c|c|c|c|}
\hline \multirow{2}{*}{$\begin{array}{l}\text { Interval } \\
\text { of offers }\end{array}$} & \multicolumn{3}{|c|}{ Greece } & \multicolumn{3}{c|}{ Spain } & \multicolumn{3}{c|}{ UK } \\
\cline { 2 - 11 } & Males & Females & Total & Males & Females & Total & Males & Females & Total \\
\hline$x<3.2$ & 4.55 & 2.08 & 3.39 & 0.76 & 14.85 & 13.74 & 1.31 & 1.89 & 1.57 \\
\hline $3.2 \leq x<3.7$ & 7.07 & 14.39 & 11.29 & 5.30 & 1.01 & 4.35 & 2.53 & 0.76 & 2.23 \\
\hline $3.7 \leq x<4.2$ & $\mathbf{4 2 . 4 2}$ & $\mathbf{2 8 . 7 9}$ & $\mathbf{3 8 . 1 7}$ & $\mathbf{2 5 . 7 6}$ & $\mathbf{3 3 . 3 3}$ & $\mathbf{3 0 . 7 6}$ & 5.05 & 3.03 & 4.47 \\
\hline $4.2 \leq x<4.7$ & $\mathbf{4 2 . 4 2}$ & $\mathbf{4 4 . 7 0}$ & $\mathbf{4 3 . 3 6}$ & 18.94 & 12.63 & 15.78 & 17.17 & 12.12 & 15.56 \\
\hline $4.7 \leq x<5.2$ & 1.52 & 6.06 & 4.82 & $\mathbf{4 4 . 7 0}$ & $\mathbf{3 4 . 3 4}$ & $\mathbf{3 9 . 1 5}$ & $\mathbf{4 9 . 4 9}$ & $\mathbf{4 1 . 6 7}$ & $\mathbf{4 6 . 6 8}$ \\
\hline $5.2 \leq x<5.7$ & 1.52 & 0 & 1.52 & 1.52 & 0 & 1.52 & 12.12 & 21.97 & 17.51 \\
\hline $5.7 \leq x$ & 0.51 & 0 & 0.51 & 1.52 & 1.01 & 1.26 & 11.11 & 17.42 & 14.34 \\
\hline
\end{tabular}

NOTE: The most frequent offers by interval are in bold characters.

In Table 4 we show the rate of rejections per country by salary offers' interval. We include the percentage of rejected offers distinguishing between male and female subjects in each country.

Regarding responders' behavior, we observe that the rejection rate in the three countries is approximately $30 \%$. Additionally, in all countries the rejection rate decreases as offers increase. As far as gender differences are concerned, note that in Spain and in Greece the percentage of rejected offers is higher for females than for males. On the contrary, males in the UK reject more than females. This result receives a strong support if we compare offers above the 3.7-4.2 m.u. interval.

\section{TABLE 4}

PERCENTAGE OF REJECTED OFFERS, BY INTERVALS

\begin{tabular}{|c|c|c|c|c|c|c|}
\hline \multirow{2}{*}{$\begin{array}{l}\text { Interval } \\
\text { of offers }\end{array}$} & \multicolumn{2}{|c|}{ Greece } & \multicolumn{2}{c|}{ Spain } & \multicolumn{2}{c|}{ UK } \\
\cline { 2 - 7 } & Males & Females & Males & Females & Males & Females \\
\hline$x<3.2$ & 66.67 & 81.82 & 100 & 88.57 & 83.33 & 66.67 \\
\hline $3.2 \leq x<3.7$ & 27.27 & 81.82 & 0 & 100 & 100 & 66.67 \\
\hline $3.7 \leq x<4.2$ & 24.39 & 44.44 & 0 & 55.26 & 100 & 57.14 \\
\hline $4.2 \leq x<4.7$ & 2.56 & 16.35 & 0 & 32.43 & 75.68 & 38.46 \\
\hline $4.7 \leq x<5.3$ & 0 & 11.11 & 0 & 10.68 & 34.12 & 14.71 \\
\hline $5.2 \leq x<5.7$ & 0 & 0 & 0 & 50 & 19.35 & 0 \\
\hline $5.7 \leq x$ & 0 & 0 & 0 & 0 & 13.79 & 0 \\
\hline
\end{tabular}


Salaries (accepted offers) present the same pattern as offers (see Table 2). We find significant differences across countries. Overall, salaries are significantly higher in the UK (5.19, on average) than in any of the other two countries (averages of 4.55 and 4.21 for Spain and Greece, respectively). Therefore, in terms of salaries, we observe a ranking with UK in the first, Spain in the second and Greece in the third position. Interestingly, observed salaries reproduce the ranking of the three countries in terms of the macroeconomic indicators like GDP and industrial and services earnings, presented in Table A (see Appendix A). This implies that the observed differences may depend on country differences on the levels of income and/or other macroeconomic determinants of subjects' opportunity costs and target earnings.

Figure 3 presents the evolution of salaries over time, by country. We observe similar patterns as with respect to posted offers. Figure 4 presents salaries by country and by gender. Likewise the case of offers, salaries in the UK are always above the salaries in Greece and Spain.

FIGURE 3

EVOLUTION OF SALARIES BY COUNTRY

(Average per period)

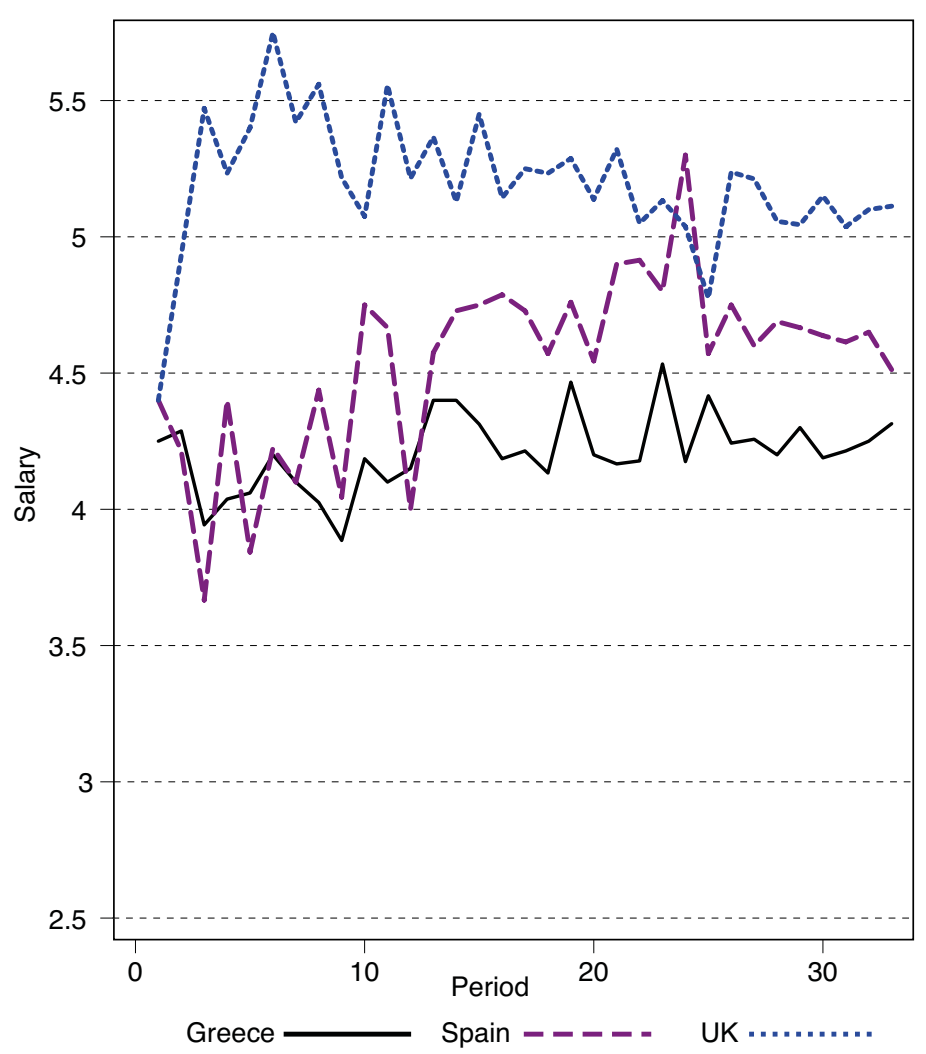


FIGURE 4

EVOLUTION OF SALARIES BY EMPLOYEE'S GENDER

(Average per period)

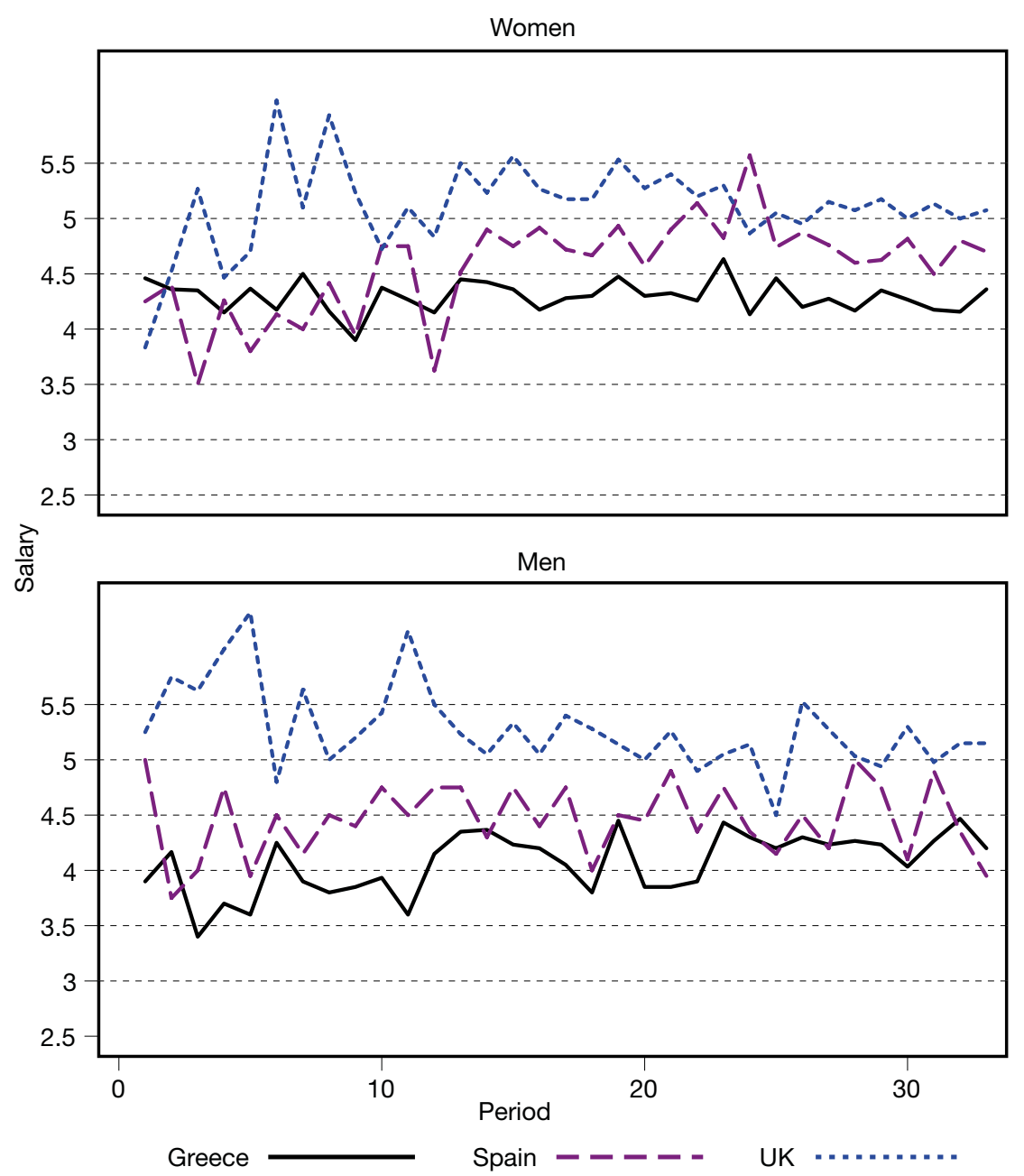

In the next section we discuss the results in more detail using regression analysis.

\subsection{Econometric analysis}

Table 5 reports results from the estimation of the models of offers, capturing the main features of employer behavior. We estimate a random effects GLS models to explain the effects of our explanatory variables affects the offers made by subjects. In the first model estimate overall pool and, in the others, we separate our data by 
gender. The explanatory variables in all models are: period $(\mathrm{T})$, certainty equivalent and country dummies (Spain and UK). The overall estimation indicates that Greek and Spanish employers have a similar behavior, however British employers' behavior differ from Greeks. In fact, British make higher offers than the others. As far as gender differences are concerned, offers made by Spanish females are not significantly different from the ones made by Greek females. However, offers made by British females are significantly higher than offers made by females in Spain and Greece.

In males' estimation, we observe that the highest wage offers are made by British employers in the first, Spanish in the second and Greek in the third place.

TABLE 5

MODELS OF OFFERS

\begin{tabular}{|l|c|l|c|l|c|l|}
\hline & \multicolumn{2}{|c|}{ GLS(Overall) } & \multicolumn{2}{c|}{ GLS(Male) } & \multicolumn{2}{c|}{ GLS(Female) } \\
\hline Constant & 4.197 & $(0.245)^{* * *}$ & 4.448 & $(0.348)^{* * *}$ & 3.938 & $(0.286)^{* * *}$ \\
\hline T & 0.013 & $(0.005)^{* * *}$ & 0.015 & $(0.005)^{* * *}$ & 0.012 & $(0.008)$ \\
\hline Certainty equivalent & -0.066 & $(0.038)^{*}$ & -0.104 & $(0.057)^{*}$ & -0.029 & $(0.039)$ \\
\hline Spain & 0.010 & $(0.357)$ & 0.385 & $(0.175)^{* *}$ & -0.193 & $(0.571)$ \\
\hline UK & 0.870 & $(0.135)^{* * *}$ & 0.762 & $(0.162)^{* * *}$ & 1.046 & $(0.227)^{* * *}$ \\
\hline
\end{tabular}

NOTE: The dependent variable is Offers (Greece baseline). Number of observations: 990, 528 and 462 respectively (30, 16 and 14 individuals, 33 periods). Standard error of the estimates between parentheses. Significant estimates at the $10 \%, 5 \%$, and $1 \%$ significance level are marked with $*$, **, and ***, respectively. Wald test $($ Spain $=\mathrm{UK}) p$-values $=0.024,0.062$ and 0.045 , respectively.

Table 6 presents the results from the estimation of a model describing employees' behavior. Specifically, we estimate the effects of the explanatory variables on employees' probability to reject a given wage offer. As we would expect, higher offers entail a lower rejection probability. This may be due to the fact that employees tend to accept with total certainty offers above a given (high) threshold and reject all offers below another (low) threshold. Overall, we observe no differences among

TABLE 6

MODELS FOR THE REJECTION PROBABILITIES BY GENDER

\begin{tabular}{|l|c|l|r|l|c|l|}
\hline & \multicolumn{2}{|c|}{$\mathbf{d y} / \mathbf{d x}(\mathbf{O v e r a l l})$} & \multicolumn{2}{c|}{$\mathbf{d y} / \mathbf{d x}(\mathbf{M a l e})$} & \multicolumn{2}{c|}{$\mathbf{d y} / \mathbf{d x}(\mathbf{F e m a l e})$} \\
\hline Offer & -0.324 & $(0.042)^{* * *}$ & -0.305 & $(0.108) * * *$ & -0.321 & $(0.040)^{* * *}$ \\
\hline T & -0.002 & $(0.002)$ & -0.006 & $(0.003)^{* *}$ & 0.001 & $(0.002)$ \\
\hline Certainty equivalent & 0.031 & $(0.016)^{*}$ & 0.023 & $(0.018)$ & 0.037 & $(0.024)$ \\
\hline Spain & 0.057 & $(0.126)$ & -0.162 & $(0.103)$ & 0.076 & $(0.102)$ \\
\hline UK & 0.336 & $(0.135)^{* *}$ & 0.511 & $(0.172)^{* * *}$ & 0.027 & $(0.130)$ \\
\hline
\end{tabular}

NOTE: Marginal effects after random effects probit regression (Greece baseline). Number of observations: 990, 528 and 462 respectively (30, 16 and 14 individuals, 33 periods). Standard error of the estimates between parentheses. Significant estimates at the $10 \%, 5 \%$, and $1 \%$ significance level are marked with *, **, and ***, respectively. Wald test $($ Spain $=\mathrm{UK}) p$-values $=0.035,0.003$ and 0.693 , respectively. 
employees from Greece and Spain. On the contrary, British employees have a higher probability of rejecting a given salary. Specifically, British male-employees are more likely to reject a given offer than other males. However, no differences of rejection probabilities among countries are found for female-employees.

In a similar way as Table 6, Table 7 presents the results from the estimation of a model describing employees' behavior each country. In this estimation, we include a male variable where we can see that Greek and Spanish females reject with a higher probability, whereas in the UK, females reject less than males.

TABLE 7

MODELS FOR THE REJECTION PROBABILITIES BY COUNTRY

\begin{tabular}{|l|c|l|r|r|r|l|}
\hline & \multicolumn{2}{|c|}{$\mathbf{d y} / \mathbf{d x}(\mathbf{G r e e c e})$} & \multicolumn{2}{c|}{$\mathbf{d y} / \mathbf{d x}(\mathbf{S p a i n})$} & \multicolumn{2}{c|}{$\mathbf{d y} / \mathbf{d x}(\mathbf{U K})$} \\
\hline Offer & -0.587 & $(0.179) * * *$ & -0.225 & $(0.036)^{* * *}$ & -0.405 & $(0.075)^{* * *}$ \\
\hline $\mathrm{T}$ & -0.003 & $(0.003)$ & -0.001 & $(0.003)$ & -0.006 & $(0.003)^{*}$ \\
\hline Certainty equivalent & 0.045 & $(0.048)$ & 0.130 & $(0.046)^{* * *}$ & 0.027 & $(0.019)$ \\
\hline Male & -0.248 & $(0.134) *$ & $-0,350$ & $(0.057)^{* * *}$ & 0.297 & $(0.126)^{* *}$ \\
\hline
\end{tabular}

NOTE: Marginal effects after random effects probit regression. Number of observations: 330 (30 individuals and 33 periods). Standard error of the estimates between parentheses. Significant estimates at the $10 \%, 5 \%$, and $1 \%$ significance level are marked with $*, * *$, and $* * *$, respectively.

\section{Conclusions}

In this paper, using an UG with a labor market framing, we study behavior of subjects from Greece, Spain and the UK. Sharp differences are observed between the two Mediterranean countries and the UK that may depend on country differences on the levels of income and/or other macroeconomic determinants of subjects' opportunity costs. Namely, higher offers and lower propensity to accept in the UK could be the result of the country's long history of unionization and a higher standard of living affecting beliefs on both sides of the game. A large part of these differences are due to gender-specific patterns. On one hand, females-employers in the UK are among the most generous proposers ever reported on UG experiments. On the other hand, male-employees from the UK are those most likely to reject a given offer.

Distinguishing by gender, we observe that offers made by Spanish females are not significantly different from the ones made by Greek females. Furthermore, offers made by British females are significantly higher than offers made by Spanish and Greek females. Salaries present the same pattern as offers. With respect to the rejection rate, we find that Greek and Spanish women reject more than men whereas in the UK the contrary holds, namely men reject more than women.

The recent economic crisis in Europe has triggered many discussions on the role of country differences in the functioning of the markets and policy makers should not underestimate this fact. 
Our results are rather specific to the labor market. Specifically, we have found that British subjects have behaved in a fairer way than their South-European counterparts. Thus, the British pool has generated more efficiency despite the higher willingness to reject shown by the British employee-subjects. It will remain unanswered here whether the differences discussed above are the cause (as a pre-existing cultural feature) or the result of larger scale differences, but it seems that a clear North-South component exists.

\section{References}

Botelho, A., Harrison, G. W., Hirsch, M. A., \& Rutstrom, E. E. (2001). Bargaining behavior, demographics and nationality: A reconsideration of the experimental evidence (NIMA Working Paper No. 16). Universidad do Minho.

Camerer, C., \& Fehr, E. (2004). Measuring social norms and preferences using experimental games: A guide for social scientists. In J. Henrich, R. Boyd, S. Bowles, C. Camerer, E. Fehr \& H. Gintis (Eds.), Foundations on Human Sociality: Economic Experiments and Ethnographic Evidence from Fifteen Small-Scale Societies (pp. 55-95). Oxford University Press. http://dx.doi.org/10.2139/ssrn.299143

Chuah, S.-H., Hoffmann, R., Jones, M., \& Williams, G. (2007). Do cultures clash? Evidence from cross-national ultimatum game experiments. Journal of Economic Behavior and Organization, 64, 35-48. https://doi.org/10.1016/j.jebo.2006.04.006

Chuah, S.-H., Hoffmann, R., Jones, M., \& Williams, G. (2009). An economic anatomy of culture: Attitudes and behaviour in inter- and intra-national ultimatum game experiments. Journal of Economic Psychology,30, 732-744. https://doi.org/10.1016/j.joep.2009.06.004

Croson, R., \& Buchan, N. (1999). Gender and culture: International experimental evidence from trust games. The American Economic Review, Papers and Proceedings, 89, 386391. https://www.jstor.org/stable/117141

Eckel, C., \& Grossman, P. (2001). Chivalry and solidarity in ultimatum games. Economic Inquiry, 39, 171-188. https://doi.org/10.1111/j.1465-7295.2001.tb00059.x

Eckel, C., \& Grossman, P. (2008). Differences in the economic decisions of men and women: Experimental evidence. In C. Plott \& V. Smith (Eds.) Handbook of Experimental Economics Results Volume 1 (pp. 509-519). Elsevier. https://doi.org/10.1016/S15740722(07)00057-1

Filippin, A., \& Crosetto, P. (2016). A reconsideration of gender differences in risk attitudes. Management Science, 62(11), 3138-3160. https://doi.org/10.1287/mnsc.2015.2294

Fischbacher, U. (2007). z-Tree: Zurich toolbox for readymade economic experiments. Experimenter's manual. Experimental Economics, 10(2), 171-178.

García-Gallego, A., Georgantzís, N., \& Jaramillo-Gutiérrez, A. (2008). Ultimatum salary bargaining with real effort. Economics Letters, 98(1), 78-83. https://doi.org/10.1016/ j.econlet.2007.04.009

García-Gallego, A., Georgantzís, N., \& Jaramillo-Gutiérrez, A. (2012). Gender differences in ultimatum games: Despite rather than due to risk attitudes. Journal of Economic Behavior and Organization, 83(1), 42-49. https://doi.org/10.1016/j.jebo.2011.06.012 
Henrich, J., Boyd, R., Bowles, S., Camerer, C., Fehr, E., Gintis, H., \& McElreath, R. (2001). In search of homo economicus: Behavioral experiments in 15 small-scale societies. The American Economic Review, Papers and Proceedings, 91, 73-78.

Henrich, J., McElreath, R., Barr, A., Ensminger, J., Barrett, C., Bolyanatz, A., Cardenas, J.C., Gurven, M., Gwako, E., Henrich, N., Lesorogol, C., Marlowe, F., Tracer, D., Ziker, J. (2006). Costly Punishment Across Human Societies. Science, 312(5781), 1767-1770.

Henrich, J., Ensminger, J., McElreath, R., Barr, A., Barrett, C., Bolyanatz, A., Cardenas, J. C., Gurven, M., Gwako, E., Henrich, N., Lesorogol, C., Marlowe, F., Tracer, D., \& Ziker, J. (2010). Markets, Religion, Community Size, and the Evolution of Fairness and Punishment. Science, 327(5972), 1480-1484.

Hofstede, G. (1991). Cultures and organizations: Software of the mind. McGraw-Hill.

Inglehart, R. (2000). Culture and democracy. In L.E. Harrison \& S.P. Huntington (Eds.), Culture Matters: How Values Shape Human Progress (pp. 80-97). Basic Books.

Oosterbeek, H., Sloof, R. S., \& van de Kuilen, G. (2004). Cultural differences in ultimatum game experiments: Evidence from a meta-analysis. Experimental Economics, 7(2), 171188.

Roth, A. E., Prasnikar, V., Okuno-Fujiwara, M., \& Zamir, S. (1991). Bargaining and market behavior in Jerusalem, Ljubljana, Pittsburg and Tokyo: An experimental study. The American Economic Review, 81(5), 1068-1095. https://www.jstor.org/stable/2006907

Saad, G., \& Gill, T. (2001). Sex differences in the ultimatum game. Journal of Bioeconomics, 3(2-3), 171-193.

Solnick, S. J. (2001). Gender differences in the ultimatum game. Economic Inquiry, 39(2), 189-200. https://doi.org/10.1111/j.1465-7295.2001.tb00060.x 


\section{APPENDIX A \\ Macroeconomics indicators}

In Table A we include, for each country, data taken from the Eurostat database, referred to several macroeconomic magnitudes for the year in which our experimental sessions took place. Specifically, the table includes data for the GDP per capita, inflation rate, minimum wage, unemployment rate by gender, the gender pay gap in unadjusted form and the average gross annual earnings in industry and services.

TABLE A

SOME MACROECONOMICS INDICATORS FOR THE THREE COUNTRIES CONSIDERED

\begin{tabular}{|l|r|r|r|r|}
\hline & & Greece & \multicolumn{1}{c|}{ Spain } & \multicolumn{1}{c|}{ UK } \\
\hline GDP per capita & & 92.1 & 101 & 121.8 \\
\hline Inflation rate & & 2.4 & 3.1 & 1.4 \\
\hline Minimum wage & & 605 & 526 & 1,106 \\
\hline \multirow{3}{*}{ Unemployment rate by gender } & Total & 9.7 & 11.1 & 5 \\
\cline { 2 - 5 } & Males & 6.2 & 8.2 & 5.5 \\
\cline { 2 - 5 } & Females & 15 & 15.3 & 4.3 \\
\hline Gender pay gap in unadjusted form & & 11 & 18 & 22 \\
\hline Average gross annual earnings in industry and services & & $16,738.5$ & 19,220 & $38,792.5$ \\
\hline
\end{tabular}

NOTE: GDP per capita in purchasing power standards (PPS) (EU-27=100). Inflation rate calculated as the annual average rate of change in Harmonized Indices of Consumer Prices. Minimum wage expressed in Euros per month. Unemployment rate by gender calculated as a \% of the labor force, taking persons aged 15-74 who were: a) without work during the reference week; b) currently available for work; c) actively seeking work. Gender pay gap in unadjusted form calculated as the difference between men's and women's average gross hourly earnings as a $\%$ of men's average gross hourly earnings. Average gross annual earnings in industry and services taken from the full-time employees in firms with 10 or more employees.

SOURCE: Eurostat data base. Data referred to year 2003. 


\section{APPENDIX B \\ Instructions to Experimental Subjects ${ }^{10}$}

You are going to participate in an experiment about individual decision making, that will last approximately 90 minutes. You must follow the instructions carefully and, depending on your performance, you may earn a considerable amount of money. The context in which you will have to take your decisions is described below.

This session will consist of two main parts:

- First part: 30-35 rounds of a salary-and-task-negotiation session.

- Second part: task-performing and payment.

\section{- First Part:}

An equal number of employers and employees are in a group of 20 individuals. At the beginning of the session, you will be randomly assigned the role of employer or employee. In each period, you will be randomly matched with a player of the other type (if you are an employer, you will be matched with an employee and vice versa). The experiment will be repeated over 30 to 35 periods (randomly determined by the server).

In each period, each employer-employee pair is faced with the following situation: The employer offers the employee a share from a 10 m.u. profit yielded from the task (filling 20 envelopes numbered, from 1 to 20, with their respective one-page letter, also numbered from 1 to 20 ) which will be performed (in the second part of the session) by the employee. If the employee accepts, the task will have to be performed by the employee (see "Second Part") and the two players' earnings are determined as proposed by the employer. Otherwise, the task is not performed and both players earn nothing.

If you are an employer, your decision will consist of offering a salary to the employee. Such a salary will be a quantity between 0 and 10 m.u., in multiples of 0.10 m.u.. If you are an employee, your decision will consist of accepting or rejecting the salary offered by the employer.

\section{- Second part:}

Your payment (and the tasks to perform if you are an employee) will be determined according to the outcome of five periods, which will be randomly chosen among the total number of periods played during this session. A minimum of $90 \%$ (at least 18 out of 20 envelopes must contain the correct sheet) reliability will be required for each task unit to be considered successfully performed.

\footnotetext{
10 This is the version of the instructions given to subjects in the UK. In Greece and Spain, the subjects were given the corresponding instructions in Greek and Spanish, respectively. The monetary units used were the corresponding of each country (pounds in the UK and euro in Greece and Spain).
} 


\section{APPENDIX C \\ Questionnaire}

\section{Control Question}

Imagine you are assigned the role of an "employee" in the following hypothetical market situation: An equal number of employers and employees are in a group of 20 individuals, forming random employee-employer pairs. You are going to negotiate your share over a total of $10 \mathrm{~m}$.u. earned by one of the employers from the task you will perform (filling 20 envelopes numbered, from 1 to 20, with their respective one-page letter, also numbered from 1 to 20). If you accept the salary, you will perform the task and earnings for both, you and your employer, will be determined as proposed by the employer. If you reject the salary, the task is not performed and you both earn nothing. Alternatively, to your earnings and task-performing obligations, you may prefer a certain payoff, whose value is provided below, under 20 different scenarios. Please mark with an " $\mathrm{X}$ " your preferred option in each one of the following scenarios:

- SCENARIO 1: You are offered an alternative of a certain payment of $0.5 \mathrm{~m} . \mathrm{u}$.

Do you prefer the certain payoff?

Or your earnings from the above hypothetical market situation?

- SCENARIO 2: You are offered an alternative of a certain payment of 1 m.u.

Do you prefer the certain payoff?

Or your earnings from the above hypothetical market situation?

- SCENARIO 3: You are offered an alternative of a certain payment of $1.5 \mathrm{~m} . \mathrm{u}$.

Do you prefer the certain payoff?

Or your earnings from the above hypothetical market situation?

- SCENARIO 20: You are offered an alternative of a certain payment of 10 m.u.

Do you prefer the certain payoff?

Or your earnings from the above hypothetical market situation? 